\title{
Multiteaming in the Workplace: Challenges for Human Resources Policies and Organizational Development
}

\author{
OANA C. FODOR \\ Department of Psychology, Babeș-Bolyai University
}

\section{Multiteaming - what it is, why is it relevant for practitioners and researchers}

The way work gets done has changed radically in the past years. As the complexity of job requirements have increased, most organizations have switched from individual work to teams or team based structures such as multi-teaming or multiple team membership (MTM) (Mathieu, Hollenbeck, van Knippenberg, \& Ilgen, 2017).

MTM is a form of work design whereby employees take part in multiple projects and work teams during a given time frame. While such a way of organizing work within organizations is not new, it is definitely on the rise. $65 \%$ up to $95 \%$ of employees across the globe operating in knowledge intensive industries currently work in a MTM setting (O'Leary et al., 2011). The average number of teams they are concurrently part of is four (Mortensen et al., 2007) and such teams can span across the boundaries of their main organization. Organizations in Romania are no exception. Multi-teaming is a frequent choice for (and not limited to) companies operating in the information technology (IT) sector, financial, management and human resources consultancy, as well as for research and development departments across manufacturing industries (e.g. automotive).
Multi-teaming is a popular work design choice for several reasons. First, the problems that organizations operating in these fields have to solve are complex and require pooling together highly specialized experts in order to deliver expected performance. For instance, an $R \& D$ engineering team designing the "smart" cars of the future draws on the expertise of automotive engineers, software developers and hardware specialists. An IT project team designing a banking application requires the involvement of banking specialists, user experience specialists, software developers and testers. As expertise is expensive, organizations strive to cut costs by reducing "bench time" (i.e. the amount of time where the contribution of a team member is not needed and the expert sits idle awaiting for tasks), and assigning them to multiple teams. Second, the choice of multi-teaming is also encouraged by the technological developments that allow virtual communication, and, thus, facilitate leveraging global talent with no constraints and for the precise amounts of time such global talent is needed. Third, the pressure for adopting multi-teaming is fostered by the rise of the so-called "gig economy" (i.e. a market that promotes short-term contracting of independent workers) (Mortensen \& Gardner, 2017). In fact, an increasing number of highly skilled workers give up the traditional and 
confining working relations with a single organization; they strive for more flexibility and control of their assignments and choose to free-lance by taking up multiple projects with different, even competing organizations at the same time (Ashford, Caza \& Reid, 2018).

Empirical research on the performance and well-being implications of multi-teaming (the very reason of prefering this arrangement) is paradoxically scant in comparison to the frequent adoption of this work design in practice. However, I will build on the available data and theories in order to describe the predictable challenges, as well as the opportunities stemming out of this work setting. I conclude by articulating the main implications of multiteaming for Human Resources (HR) policies and Organizational Development (OD) measures.

\section{Challenges of multiteaming in organizations}

So far, extant research showed inconclusive evidence regarding the link between the number of teams an employee is part of and work performance. Some studies showed a negative association between the number of teams an employee works in and individual and team performance (Brake et al., 2018; Cummings \& Haas, 2012), while other studies showed a positive association between the number of teams and team performance (Bertolotti et al., 2015). Additionally, there is building evidence that multiteaming brings additional costs for employees' well-being, as MTM is associated with increased interpersonal frictions, less social support and reduced work engagement (Pluut, Fleștea \& Curșeu, 2014).

These "gloomy" results regarding the implications of MTM for performance and employee well-being are related to the fact that, when simultaneously belonging to multiple teams within an organization, employees have to cope with some challenging work conditions that should be foreseen and addresed by both HR policies and OD measures.

\#1: One implication of multiteaming for employees is the need to periodically switch contexts among the teams $\mathrm{s} / \mathrm{he}$ is part of in order to deliver the required outputs. A team context is defined by the colleagues that are part of that team, the tasks one has to perform, as well as the technologies and procedures that one has to use within that team. Time fragmentation between teams, as well as the level of similarity among the teams contexts one is part of are two of the parameters that are claimed to explain and/or affect the influence of MTM on individual and organizational performance and well-being. While switching from a project team to another when experiencing idle time on one of them improves productivity, time allocation becomes challenging as the number of teams one is part of increases, and unexpected project events occur simultaneously demanding an employee's attention. Transitioning among very different team contexts (i.e. different task requirements and team cultures) is even more taxing. Multiteaming can thus become too much of a demand on the limited resources pool that an employee has at his/her disposal.

\#2: Belonging to multiple teams also means relational tensions generated by difficulties in intra and inter-team coordination. When an employee is simultaneously part of multiple teams, s/he might not be able to promptly respond to demands, which is a common source of team process conflict (i.e. arguing on who should do what and when within a team). In turn, process conflict frequently transforms in relational conflicts (i.e. arguing on personal qualities and intentions), which impedes both performance and well-being (deWit, Jehn \& Greer, 2012).

\#3: Multiteaming increases an employee's, as well as the organization's interconnectivity. On the positive side, social capital theory (Kwon \& Adler, 2014) highlights the potential resource gains (i.e. diverse experiences, perspectives and know-how) that an employee can achieve via multi-teaming and argues that such social capital is key for learning and performance. When one has access to best practices in different teams, one can transfer such knowledge from a team to another in order to deal with unpractical organizational routines. On the dark side, however, the 
interconnectivity fostered by multiteaming also comes with a faster deployment of performance shocks within the organization. When multiple organizational teams share many members, a shock in one team (i.e. a technical problem that needs to be addressed, or interpersonal frictions arising in one of the teams) ripples in all the other teams that those employees are part of via attention shift (for the technical problem) and emotional contagion (for the interpersonal frictions) mechanisms.

\#4: When concurrently working in multiple teams (most often than not) lead by different leaders, employees face challenges related to the less clear supervision. In such a work setting, no team leader/manager has a clear overview of the employee's workload and performance. Additionally, the same employee is possibly facing very different leadership styles and requirements that requires effort to handle.

\section{Implications of multiteaming for HR policies and OD Measures}

The new world of work includes more flexibility in work arrangements, increased complexity, flatter structures and less clear supervision. These are all encompassed by multiteaming as a work design. While MTM can definitely foster important organizational benefits (i.e. facilitate productivity, learning and innovation diffusion), it also entails major challenges: increased workload, job strain, relational tensions and „ripple effects”. Given that HR management refers to "building the workforce and creating the human performances that the organization needs" (Boxall \& Purcell, 2016, p. 28), I argue that HR policies can and should address the shortcomings of working in an MTM setting in order to reap its benefits.

Given the particularities of multiteaming, an important question is related to what are the qualities that would make an employee thrive in this work setting. By building on the work features related to MTM (i.e. task switching, time fragmentation, relational tensions), and on extant literature I argue that some of the required qualities for performing in MTM settings are related to: cognitive flexibility (i.e. individuals' general ability to switch between tasks and goals and effectively manage novelty) (Buttelmann \& Karbach, 2017; Hirt, Devers, \& McCrea, 2008); time management (i.e. individuals' ability to adjust time allocation in line with priorities), ambivalence tolerance (i.e. tolerance to experiencing conflicting emotions) (Ashford, Caza \& Reid, 2018) and teamworking (i.e. en employees' ability to interact with colleagues in order to reach a common goal, while preserving a healthy climate). Research is still needed on testing the predictive power of these factors for performance and well-being in an MTM setting. Staffing procedures could then be adapted in order to include selection criteria that fit those requirements, while learning and development programs could be designed in order to train these skills.

An important challenge for HR policies related to performance evaluation and management is the lack of clear supervision associated with MTM. A common organizational practice is to ask the administrative leader (i.e. usually the departmental leader in a matrix organization) to carry on this process or, alternatively, the leader of the team the employee spends most of his/her working time. Both of these practices build on fragmented views of such an employee's performance and can easily be associated with perceptions of organizational injustice. Performance management should move towards a better integration of the employee's working experience, by also relying on all leaders supervising and employee's work.

Finally, multiteaming comes with great potential for fostering organizational learning and performance, due to the increased connectivity. Organizational development measures could target ways of facilitating knowledge deployments from an organizational team to another. Training leaders to reinforce norms that foster knowledge sharing across teams and lead by example is such a measure (Mortensen \& Gardner, 2017).

To conclude, it is not enough to want to optimize employee and organizational 
productivity by assigning them to multiple teams. If organizations strive to be successful by implementing this work design measure, then they should definitely follow-up with aligned HR policies and OD measures that buffer the negative effects of multiteaming (i.e. time fragmentation, context switching etc.) and foster the benefits related to reducing bench time and knowledge deployment. Finally, more research is needed in order to assist organizations in adjusting these policies.

\section{References}

Ashford, S. J, Caza, B. B. \& Reid, E. M. (2018). From surviving to thriving in the gig economy: A research agenda for individuals in the new world of work. Research in Organizational Behavior, https://doi.org/10.1016/j.riob.2018.11.001

Bertolotti, F., Mattarelli, E., Vignoli, M., \& Macrì, D. M. (2015). Exploring the relationship between multiple team membership and team performance: The role of social networks and collaborative technology. Research Policy, 44, 911-924. http://dx.doi.org/10.1016/j.respol.2015.01.019

Boxall, P., \& Purcell, J. (2016). Strategy and human resource management (4th ed.). Basingstoke: Palgrave.

Brake, H.J., Walter, F., Rink, F. A., Essens, P.J.M.D. \& van der Vegt, G.s. (2016). The dynamic relationship between multiple team membership and individual job performance in knowledge-intensive work. Journal of Organizational Behavior, 39, 1219-1231. http://dx.doi.org/10.1002/job.2260.
Buttelmann, F., \& Karbach, J. (2017). Development and plasticity of cognitive flexibility in early and middle childhood. Frontiers in Psychology, 8. http://dx.doi.org/10.3389/fpsyg.2017.01040.

Cummings, J. N., \& Haas, M. R. (2012). So many teams, so little time: Time allocation matters in geographically dispersed teams. Journal of Organizational Behavior, 33, 316-341. http://dx.doi.org/10.1002/job.777.

de Wit, F. R. C., Greer, L. L \& Jehn, K. A. (2012). The Paradox of Intragroup Conflict: A Meta-Analysis. Journal of Applied Psychology, 97(2), 360-390. http://dx.doi.org/10.1037/a0024844.

Hirt, E. R., Devers, E. E., \& McCrea, S. M. (2008). I want to be creative: Exploring the role of hedonic contingency theory in the positive mood-cognitive flexibility link. Journal of Personality and Social Psychology, 94(2), 214-230. http://dx.doi.org/10.1037/0022-3514.94.2.94.2.214.

Kwon, S. W., \& Adler, P. S. (2014). Social capital: Maturation of a field of research. Academy of Management Review, 39, 412-422.

Mortensen, M., \& Gardner, H. K. (2017). The Overcommitted Organization. Harvard Business Review. Retrieved from https://hbr.org/2017/09/theovercommitted-organization

Pluut, H., Flestea, A. M., \& Curs, eu, P. L. (2014). Multiple team membership: A demand or resource for employees? Group Dynamics: Theory, Research, and Practice, 18, 333-348. http://dx.doi.org/10.1037/gdn0000016. 